\title{
Short- and long-term outcomes of 1000 adult lung transplant recipients at a single center
}

\author{
Daniel Kreisel, MD, PhD, ${ }^{\mathrm{a}}$ Alexander S. Krupnick, MD, ${ }^{\mathrm{a}}$ Varun Puri, MD, ${ }^{\mathrm{a}}$ Tracey J. Guthrie, RN, ${ }^{\mathrm{a}}$ \\ Elbert P. Trulock, MD, ${ }^{\mathrm{b}}$ Bryan F. Meyers, MD, ${ }^{\mathrm{a}}$ and G. Alexander Patterson, $\mathrm{MD}^{\mathrm{a}}$
}

Objective: Lung transplantation has become accepted therapy for end-stage pulmonary disease. The objective of this study was to review a single-institution experience of adult lung transplants. Methods: We reviewed 1000 adult lung transplants that were performed at Washington University between July
1988 and January 2009.

Results: Transplants were performed for emphysema (52\%), cystic fibrosis $(18.2 \%)$, pulmonary fibrosis $(16.1 \%)$, and pulmonary vascular disease $(7.2 \%)$. Overall recipient age was $48 \pm 13$ years with an increase from $43 \pm 12$ years (July 1988-November 1993) to $50 \pm 14$ years (June 2005-January 2009). Overall incidence of primary graft dysfunction was $22.1 \%$. Hospital mortality was higher for patients who had primary graft dysfunction (primary graft dysfunction, $13.6 \%$; no primary graft dysfunction, $4 \% ; P<.001$ ). Freedom from bronchiolitis obliterans syndrome was $84 \%$ at 1 year, $38.2 \%$ at 5 years, and $12.2 \%$ at 10 years. Survival at $1,5,10$, and 15 years was $84 \%, 56.4 \%, 32.2 \%$, and $17.8 \%$, respectively. Five-year survival improved from $49.6 \%$ (July 1988-November 1993) to 62.1\% (October 2001-June 2005). Primary graft dysfunction was associated with lower survival at 1,5 , and 10 years (primary graft dysfunction: $72.8 \%, 43.9 \%$, and $18.7 \%$, respectively; no primary graft dysfunction: $87.1 \%, 59.8 \%$, and $35.7 \%$, respectively, $P<.001$ ) and lower rates of freedom from bronchiolitis obliterans syndrome (primary graft dysfunction: $78 \%, 27.5 \%$, and $8.5 \%$, respectively; no primary graft dysfunction: $85.4 \%, 40.7 \%$, and $13.1 \%$, respectively, $P=.007$ ).

Conclusions: Five-year survival has improved over the study period, but long-term outcomes are limited by bronchiolitis obliterans syndrome. Primary graft dysfunction is associated with higher rates of bronchiolitis obliterans syndrome and impaired short- and long-term survival. A better understanding of primary graft dysfunction and bronchiolitis obliterans syndrome is critical to improve outcomes. (J Thorac Cardiovasc Surg 2011;141:215-22)

During the last 3 decades, lung transplantation has evolved into established therapy for end-stage lung disease. The Registry of The International Society for Heart and Lung Transplantation indicates that 2708 lung transplants were performed worldwide in $2007 .{ }^{1}$ Despite changes in patient selection, refinements in operative techniques, and improvements in postoperative care, outcomes have remained worse compared with other organ transplants. This field faces numerous challenges, which include, but are not limited to, a shortage of donor organs, a relatively high incidence of primary graft dysfunction (PGD), and a high rate of graft failure from bronchiolitis obliterans syndrome (BOS). Our group

\footnotetext{
From The Division of Cardiothoracic Surgery, ${ }^{a}$ Department of Surgery, and The Division of Pulmonary and Critical Care Medicine, ${ }^{\mathrm{b}}$ Department of Medicine, Washington University in St Louis, Mo.

Disclosures: Authors have nothing to disclose with regard to commercial support.

Read at the 90th Annual Meeting of The American Association for Thoracic Surgery, Toronto, Ontario, Canada, May 1-5, 2010.

Received for publication May 3, 2010; revisions received Aug 23, 2010; accepted for publication Sept 2, 2010; available ahead of print Nov 22, 2010.

Address for reprints: Daniel Kreisel, MD, PhD, Associate Professor of Surgery, Assistant Professor of Pathology \& Immunology, Campus Box 8234, 660 S Euclid Ave, Washington University in St. Louis, St. Louis, MO 63110-1013 (E-mail: kreiseld@wudosis.wustl.edu).

$0022-5223 / \$ 36.00$

Copyright (c) 2011 by The American Association for Thoracic Surgery

doi:10.1016/j.jtcvs.2010.09.009
}

previously described the incidence and outcomes of complications in 706 adult and 277 pediatric lung transplants. ${ }^{2}$ The current article reports our experience with 1000 adult lung transplants that were performed at a single institution over a period of more than 2 decades. We outline temporal developments in patient selection and outcomes, and specifically examine the incidence of PGD and BOS.

\section{MATERIALS AND METHODS \\ Patient Demographics}

One thousand adult lung transplants were performed at Barnes-Jewish Hospital between July 1988 and January 2009. Results were analyzed retrospectively using a prospectively gathered database of our lung transplant program. Permission for this study was obtained from The Washington University in St Louis Institutional Review Board.

Table 1 shows demographic data for all patients. These data are broken down into quintiles in Table 2. Mean recipient age was $47.8 \pm 12.9$ years. There was an increase in mean age from $43.4 \pm 12$ years in the first quintile (July 1988 to November 1993) to $50.1 \pm 14$ years in the last quintile (June 2005 to January 2009). A total of 506 patients (50.6\%) were male, and 494 patients $(49.4 \%)$ were female. We performed bilateral lung transplants in 805 patients $(80.5 \%)$ and single lung transplants in 186 patients $(18.6 \%)$. Six patients underwent combined heart-lung transplantation, and 3 patients received bilateral lobar transplants. A total of 520 transplants $(52 \%)$ were performed for emphysema, 182 transplants $(18.2 \%)$ were performed for cystic fibrosis, 161 transplants $(16.1 \%)$ were performed for pulmonary fibrosis, 72 transplants $(7.2 \%)$ were performed for pulmonary vascular disease, 29 transplants $(2.9 \%)$ were performed for bronchiectasis, 17 


\section{Abbreviations and Acronyms \\ BOS = bronchiolitis obliterans syndrome \\ $\mathrm{COPD}=$ chronic obstructive pulmonary disease \\ $\mathrm{DCD}=$ donation after cardiac death \\ PGD = primary graft dysfunction}

transplants $(1.7 \%)$ were performed for lymphangioleiomyomatosis, and 16 transplants $(1.6 \%)$ were performed for sarcoidosis. Over the study period, there has been a marked decline in lung transplants performed for pulmonary vascular disease $(14.5 \%$ during the first quintile vs $1.5 \%$ during the last quintile) and a substantial increase in transplants for pulmonary fibrosis ( $9.5 \%$ during the first quintile vs $31.5 \%$ during the last quintile). We have also experienced a recent decline in transplants for emphysema (39.5\% during the last quintile vs $48.5 \%-66.5 \%$ during the previous 4 quintiles). Specifically, before implementation of the lung allocation score in $2005,42.9 \%$ of transplants were performed for chronic obstructive pulmonary disease (COPD), $23.9 \%$ were performed for cystic fibrosis, and $14.7 \%$ were performed for pulmonary fibrosis. After introduction of the lung allocation score, we experienced a proportional decrease in transplants for COPD (30\%) and cystic fibrosis $(19.8 \%)$ concomitant with an increase in transplants for pulmonary fibrosis $(21.8 \%)$. The mean lung allocation score at the time of transplantation was 33.5 for patients with COPD, 45.8 for patients with cystic fibrosis, and 51.3 for patients with pulmonary fibrosis. The mean time on the waiting list was $510.3 \pm 326.4$ days. For all transplants, including those performed after implementation of the lung allocation score, waiting periods were determined on the basis of the time from listing for transplantation until the day of the procedure. From the first to the third quintile the mean waiting period had steadily increased from $203.8 \pm 145.2$ days to $717.3 \pm 269.4$ days. Over the most recent 2 quintiles, the mean time on the waiting list has progressively decreased to $574.6 \pm 307$ days.

\section{Postoperative Management}

The majority of recipients received either Atgam or an interleukin 2-receptor antagonist as induction therapy. Patients were maintained on tripledrug immunosuppression consisting of steroids, a cell cycle inhibitor, and a calcineurin inhibitor. All patients underwent routine postoperative surveillance bronchoscopy, and maintenance immunosuppression was adjusted on the basis of these findings.

\section{Statistical Analysis}

Categoric data were compared with Fisher's exact or chi-square tests, and normally distributed continuous variables were compared with a 2tailed Student $t$ test. Skewed data were compared with the Wilcoxon rank-sum test. Rates for survival and freedom from BOS were calculated using the Kaplan-Meier method. Data analysis was performed using SPSS software (SPSS 11.0; SPSS Inc, Chicago, Ill).

\section{RESULTS \\ Survival}

Sixty-one patients $(6.1 \%)$ died during their initial hospital stay with a decline from $11 \%$ during the first quintile to $4.5 \%$ to $5 \%$ during the subsequent quintiles. Overall survival was $85 \%, 57.5 \%, 33.2 \%$, and $18.3 \%$ at $1,5,10$, and 15 years, respectively (Figure 1, A). The median survival times were 4.5, 6.2, and 6.8 years for the first, second, and third quintiles, respectively. We observed steady improvements in 3-year $(67 \%, 69 \%, 72.5 \%$, and $73 \%$, respectively) and 5-year survival over the first 4 quintiles $(48.5 \%, 57 \%, 58 \%$, and $62.1 \%$, respectively) and $10-$ year survival over the first 3 quintiles $(22.5 \%, 30.5 \%$, and $41.3 \%$, respectively) (Figure $1, B$ ). Although we observed progressive improvements in 1-year survival during the first 4 quintiles $(79 \%, 83 \%, 86 \%$, and $88 \%$, respectively), there was a modest decrease in 1-year survival to $84.4 \%$ during the fifth quintile. Bilateral lung transplantation was associated with better survival than single lung transplantation at all time points examined $(1$ year: $85.7 \%$ vs $82.1 \%$; 3 years: $72.1 \%$ vs $68.2 \%$; 5 years $60.1 \%$ vs $47.6 \%$; 10 years $37.3 \%$ vs $20.1 \%$ ). Survival was $61.6 \%$ and $38.4 \%$ for patients with emphysema who received bilateral lung transplants and $58.9 \%$ and $36.7 \%$ for patients with pulmonary fibrosis at 5 and 10 years, respectively, which was significantly higher than those for recipients of single lungs for both disease processes (emphysema: $43.2 \%$ and $13 \%$; pulmonary fibrosis: $44.9 \%$ and $20.8 \%$ at 5 and 10 years, respectively.)

\section{Primary Graft Dysfunction}

A total of 221 patients $(22.1 \%)$ had PGD. Notably, we did not observe marked changes in the incidence of this complication over our study period (Figure 2, A). PGD had a significant adverse effect on both short- and longterm survival. The hospital mortality for lung transplant recipients who had PGD was significantly higher than that for patients who did not have this complication $(13.6 \%$ vs $4 \%$, $P<.001)$. Survival at 1,5 , and 10 years for patients whose course was complicated by PGD was $72.8 \%, 43.9 \%$, and $18.7 \%$, respectively (Figure 2, B). Survival at these time points was significantly higher for those recipients who did not experience PGD $(87.1 \%, 59.8 \%, 35.7 \%$, respectively; $P<.001)$. Eleven patients underwent retransplantation for PGD.

\section{Bronchiolitis Obliterans Syndrome}

Freedom rates from BOS were $84 \%, 54.3 \%, 38.2 \%$, and $12.2 \%$ at $1,3,5$, and 10 years, respectively (Figure $3, A$ ). The median time from the transplant procedure to the point when BOS was diagnosed was 3.4 years; $81.9 \%$ of recipients in the first quintile did not have BOS at 1 year, which was comparable to the rates for patients in the subsequent 4 quintiles. However, for patients in the first quintile, we observed markedly lower rates of freedom from BOS at $3(39.6 \%)$ and $5(24.3 \%)$ years when compared with the remainder of the patient cohort (Figure 3, B). Nine lung retransplantations were performed for patients with BOS.

PGD was also associated with lower rates of freedom from BOS at all time points examined (Figure 3,C). In the cohort of patients who had PGD, the rates of freedom from BOS were $78 \%, 27.5 \%$, and $8.5 \%$ at 1,5 , and 10 years, respectively. Alternatively, $85.4 \%, 40.7 \%$, and 
TABLE 1. Recipient demographic data

\begin{tabular}{lc}
\hline Age (y) & $47.8 \pm 12.9$ \\
Gender (male) & $51(\mathrm{IQR}: 39-58)$ \\
Diagnosis & $506(50.6 \%)$ \\
Emphysema & \\
Cystic fibrosis & $520(52.0 \%)$ \\
Pulmonary vascular disease (PPH, & $182(18.2 \%)$ \\
$\quad$ Eisenmenger's, CHD-PH) & $72(7.2 \%)$ \\
IPF/PF & \\
Sarcoid & $161(16.1 \%)$ \\
Bronchiectasis & $16(1.6 \%)$ \\
LAM & $29(2.9 \%)$ \\
Other pulmonary disease & $17(1.7 \%)$ \\
Time on the waiting list (d) & $3(0.3 \%)$ \\
& $510.3 \pm 326.4$ \\
Type of transplant performed & $488(\mathrm{IQR}: 342-631)$ \\
Bilateral & \\
Single & $805(80.5 \%)$ \\
Heart/lung & $186(18.6 \%)$ \\
Bilateral lobar & $6(0.6 \%)$ \\
Ischemic time (min) & $3(0.3 \%)$ \\
First lung & \\
Second lung & $246.7 \pm 57.9$ \\
Length of mechanical ventilation (median, d) & $335.3 \pm 69.3$ \\
Length of stay in ICU (median, d) & $2(\mathrm{IQR}: 1-3)$ \\
Length of stay in hospital (median, d) & $3(\mathrm{IQR}: 2-5)$ \\
PGD & $15(\mathrm{IQR}: 11-23)$ \\
PTLD & $221(22.1 \%)$ \\
Hospital mortality & $55(5.5 \%)$ \\
\hline ( $)$ & $61(6.1 \%)$ \\
\hline
\end{tabular}

$I Q R$, Interquartile range $(25 \%-75 \%) ; P P H$, primary pulmonary hypertension; $C H D$ $P H$, congestive heart disease-pulmonary hypertension; IPF/PF, idiopathic pulmonary fibrosis/pulmonary fibrosis; $L A M$, lymphangioleiomyomatosis; $I C U$, intensive care unit; PTLD, posttransplant lymphoproliferative disorder.

$13.1 \%$ of transplant recipients who did not have this complication were free from BOS at the same time points $(P<.01)$.

\section{Length of Stay}

The median length of mechanical ventilation was 2 days, and the median length of stay in the intensive care unit was 3 days with no marked changes in these parameters over the study period. The median length of stay in the hospital was 15 days. This reflects a decrease from 22 days during the first quintile to 15 days for all subsequent quintiles.

\section{DISCUSSION}

This article represents the largest single-institution series of adult lung transplants that has been reported to date. The patients presented underwent transplantation during a period of more than 2 decades. Our group previously reviewed our experience with 277 pediatric and 706 adult lung recipients. The current report focuses on adult recipients only. A large portion of the 294 adult patients who have been added to the current analysis underwent transplantation since the implementation of the lung allocation score, reflecting a marked change in the composition of the recipient popu- lation. Several observations in our series highlight recent trends, such as the use of more marginal donors, and current challenges of lung transplantation, such as persistently high rates of PGD despite refinements in preservation solutions.

Survival at $1,3,5$, and 10 years has consistently improved during the first 4 quintiles. Improvements in late survival are likely to be in large part due to improvements in early survival. Factors that may have contributed to improvements in early survival and especially to the decrease in hospital mortality after the first quintile are refinements in perioperative management. Notably, the rates of freedom from BOS are markedly lower for patients in the first quintile than for those who underwent transplantation thereafter, suggesting that better management of early complications, such as PGD, acute rejection, and infections, which are known risk factors for BOS, has played a role in improvements in long-term survival after the first quintile. Moreover, with the exception of the third quintile, we have observed a progressive decline in the incidence of posttransplant lymphoproliferative disorder (Tables 1 and 2), which also may have contributed to improvements in overall survival after the first quintile. Of note, starting in the third quintile, a team of critical care physicians has been involved in the management of lung transplant recipients during their stay in the intensive care unit. Changes in our immunosuppressive regimen are likely to have contributed to improvements in long-term outcomes. This is illustrated by the results of a study that was performed during the third quintile, in which maintenance immunosuppression with tacrolimus yielded superior results compared with cyclosporine. ${ }^{3}$ Also, during the third quintile, our institution started using new treatment strategies, such as azithromycin and photopheresis, for patients with BOS. ${ }^{4,5}$ Such interventions are also likely to have contributed to improvements in overall survival. Collectively, our results indicate that the increase in overall survival is in large part due to improvements in short-term survival and probably to a lesser extent more effective management of longterm complications. Notably, a recent review of the registry of the International Society for Heart and Lung Transplantation has reached analogous conclusions. ${ }^{1}$ Compared with the fourth quintile, there was a decline in both 1- and 3-year survival during the last quintile, which can at least in part be attributed to a change in the recipient population secondary to the implementation of the lung allocation score and the acceptance of more marginal donors.

We prefer to perform bilateral rather than single lung transplants for patients with both suppurative and nonsuppurative lung diseases, such as emphysema or fibrosis. We previously reported that bilateral lung transplantation for patients with COPD is associated with better long-term survival than single lung transplantation, a finding now corroborated by others. ${ }^{6,7}$ Notably, improved long-term survival 
TABLE 2. Recipient demographic data stratified by quintiles

\begin{tabular}{|c|c|c|c|c|c|}
\hline & Quintile $1 \mathrm{~N}=\mathbf{2 0 0}$ & Quintile 2 N $=200$ & Quintile 3 N $=\mathbf{2 0 0}$ & Quintile $4 \mathrm{~N}=\mathbf{2 0 0}$ & Quintile $5 \mathrm{~N}=\mathbf{2 0 0}$ \\
\hline Date range & 07/88-11/93 & $11 / 93-01 / 98$ & 01/98-10/01 & $10 / 01-06 / 05$ & $06 / 05-1 / 09$ \\
\hline Age (y) & $43.4 \pm 12.0$ & $46.7 \pm 12.1$ & $50.5 \pm 11.0$ & $48.6 \pm 14.1$ & $50.1 \pm 14.0$ \\
\hline Gender (male) & $93(46.5 \%)$ & $101(50.5 \%)$ & $102(51.0 \%)$ & $100(50.0 \%)$ & $110(55.0 \%)$ \\
\hline \multicolumn{6}{|l|}{ Diagnosis } \\
\hline Emphysema & $108(54.0 \%)$ & $97(48.5 \%)$ & $133(66.5 \%)$ & $103(51.5 \%)$ & $79(39.5 \%)$ \\
\hline Cystic fibrosis & $33(16.5 \%)$ & $31(15.5 \%)$ & $29(14.5 \%)$ & $51(25.5 \%)$ & $38(19.0 \%)$ \\
\hline Pulmonary vascular disease & $29(14.5 \%)$ & $23(11.5 \%)$ & $7(3.5 \%)$ & $10(5.0 \%)$ & $3(1.5 \%)$ \\
\hline $\mathrm{IPF} / \mathrm{PF}$ & $19(9.5 \%)$ & $27(13.5 \%)$ & $21(10.5 \%)$ & $31(15.5 \%)$ & $63(31.5 \%)$ \\
\hline Sarcoid & $2(1.0 \%)$ & $2(1.0 \%)$ & $2(1.0 \%)$ & $2(1.0 \%)$ & $8(4.0 \%)$ \\
\hline Bronchiectasis & $5(2.5 \%)$ & $13(6.5 \%)$ & $2(1.0 \%)$ & $2(1.0 \%)$ & $7(3.5 \%)$ \\
\hline LAM & $3(1.5 \%)$ & $7(3.5 \%)$ & $5(2.5 \%)$ & $1(0.5 \%)$ & $1(0.5 \%)$ \\
\hline Other pulmonary disease & $1(0.5 \%)$ & 0 & $1(0.5 \%)$ & 0 & $1(0.5 \%)$ \\
\hline Time on the waiting list (d) & $203.8 \pm 145.2$ & $530.1 \pm 201.7$ & $717.3 \pm 269.4$ & $610.1 \pm 437.8$ & $574.6 \pm 307.0$ \\
\hline \multicolumn{6}{|l|}{ Type of transplant performed } \\
\hline Bilateral & $101(50.5 \%)$ & $147(73.5 \%)$ & $178(89.0 \%)$ & $190(96.0 \%)$ & $189(94.5 \%)$ \\
\hline Single & $99(49.5 \%)$ & $51(25.5 \%)$ & $20(10.0 \%)$ & $6(2.0 \%)$ & $10(5.0 \%)$ \\
\hline Heart/lung & 0 & $2(1.0 \%)$ & $2(1.0 \%)$ & $1(0.5 \%)$ & $1(0.5 \%)$ \\
\hline Bilateral lobar & 0 & 0 & 0 & $3(1.5 \%)$ & 0 \\
\hline $\begin{array}{l}\text { Length of mechanical } \\
\text { ventilation }\end{array}$ & 3 (IQR: 2-5) & 2 (IQR: $1-4)$ & 1 (IQR: 1-2) & 1 (IQR: 1-3) & 2 (IQR: 1-7) \\
\hline Length of stay in ICU & 4 (IQR: 3-6) & 3 (IQR: 2-6) & 2 (IQR: 2-4) & 3 (IQR: 2-5) & 4 (IQR: 2-10) \\
\hline Length of stay in hospital & 22 (IQR: 18-29) & 15 (IQR: 11-23) & 15 (IQR: 11-23) & 15 (IQR: 11-23) & 15 (IQR: 11-23) \\
\hline PGD & $46(23.0 \%)$ & $39(19.5 \%)$ & $37(18.5 \%)$ & $52(26.0 \%)$ & $47(23.5 \%)$ \\
\hline PTLD & $19(9.5 \%)$ & $9(4.5 \%)$ & $13(6.5 \%)$ & $8(4 \%)$ & $6(3 \%)$ \\
\hline Hospital mortality & $22(11.0 \%)$ & $10(5.0 \%)$ & $9(4.5 \%)$ & $10(5.0 \%)$ & $10(5.0 \%)$ \\
\hline
\end{tabular}

$I P F / P F$, Idiopathic pulmonary fibrosis/pulmonary fibrosis; $L A M$, lymphangioleiomyomatosis; $I C U$, intensive care unit; $P T L D$, posttransplant lymphoproliferative disorder; $I Q R$, interquartile range.

after bilateral lung transplantation in this patient population may in part be due to lower rates of BOS. ${ }^{8}$ Notably, a recent analysis of the United Network for Organ Sharing database showed that survival after bilateral and single lung transplantation was comparable in patients aged 60 years or more. ${ }^{9}$ The choice of single lung transplantation for nonsuppurative lung diseases is often guided by the shortage of donor organs and the desire to perform transplantation in 2 recipients rather than 1 recipient. ${ }^{10}$ Because advances such as ex vivo reconditioning will probably expand the availability of donor lungs in the future, bilateral lung transplantation is likely to be more universally used.

One of the most striking findings is the impact that PGD has on both short- and long-term outcomes. PGD after lung transplantation, formerly referred to as reimplantation response, is widely perceived to be a consequence of ischemia-reperfusion injury. Both experimental and clinical studies have suggested that compared with other organs, lungs are particularly susceptible to ischemia-reperfusion injury. ${ }^{11}$ Numerous experimental studies have shown that extracellular solutions are superior for lung preservation when compared with intracellular solutions. ${ }^{12}$ Although many clinical studies have confirmed these observations, some studies have yielded conflicting results. ${ }^{13,14}$ Our group switched from intracellular to extracellular solutions for lung preservation in May 2001. Nevertheless, the rates of
PGD have remained stable over our study period. Notably, a recent study found that a non-COPD recipient diagnosis is a risk factor for the development of PGD. ${ }^{15}$ Therefore, a progressive decrease in transplants for COPD from $66.5 \%$ during the third quintile to $39.5 \%$ during the fifth quintile may have contributed to steady rates of PGD despite improvements in lung preservation. Another potential reason for the persistently high incidence of PGD is a progressive shift toward acceptance of marginal donors in our program. To this end, Whitson and colleagues ${ }^{15}$ have identified donor age and donor smoking history as significant risk factors for PGD. An important consideration in this context is that the relative shortage of donor lungs has led to the use of donation after cardiac death (DCD), as well as ex vivo perfusion and reconditioning of marginal lungs. Although there are no definitive data available on whether the use of DCD is associated with a higher incidence of PGD, the period of relative warm ischemia inherent to this procedure poses a potential concern. In our own experience with 11 lung transplants, for which we used DCD, the incidence of grade 3 PGD was $36 \%$, which was twice as high as in patients who received lungs from brain-dead donors during the same time period. ${ }^{16}$ Our findings contrast with those of Erasmus and colleagues ${ }^{17}$ who recently reviewed outcomes in 21 patients receiving lungs from non-heart-beating donors. Rates of PGD in this cohort were equivalent to those of a control 

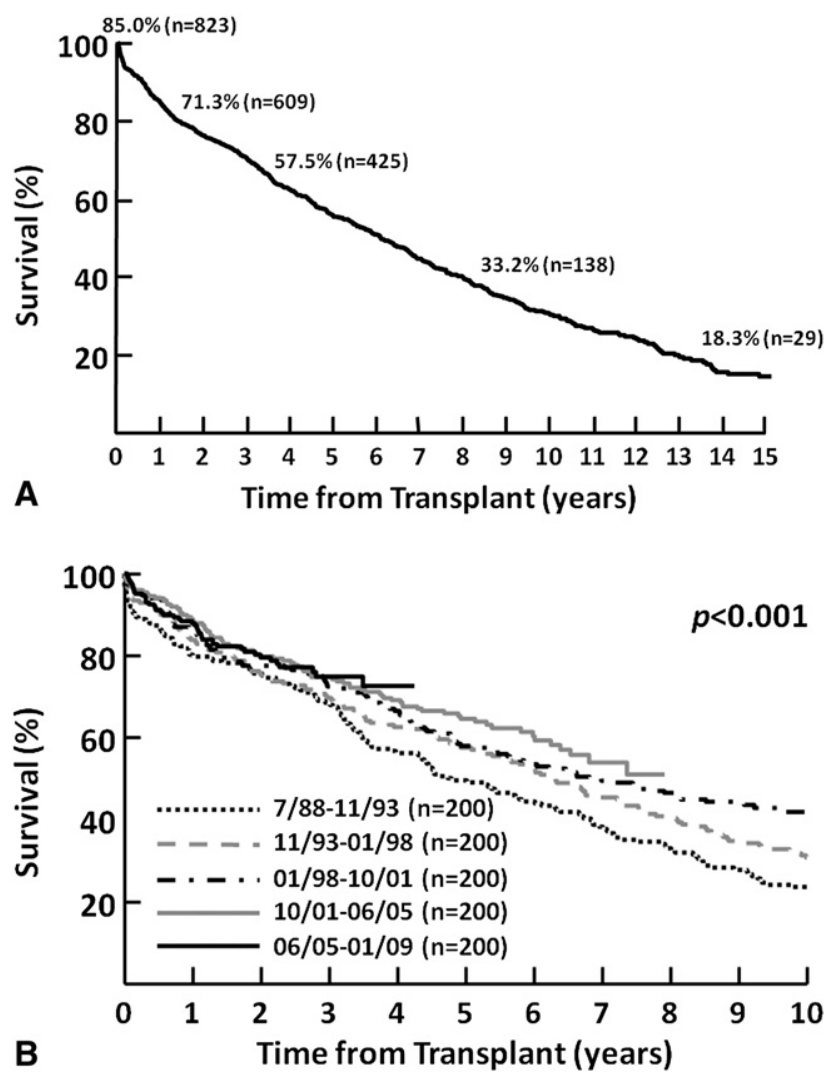

FIGURE 1. A, Survival after lung transplantation $(\mathrm{n}=1000)$. B, Survival after lung transplantation stratified by quintile.

group of 77 patients who received lungs from heart-beating donors. Moreover, in their series there were no differences in 2-year survival between lung recipients who received organs from heart-beating or non-heart-beating donors. Recent work from the group at Toronto General Hospital has demonstrated that treatment of human lungs with an adenoviral vector encoding interleukin-10 during a period of ex vivo perfusion leads to functional improvement. ${ }^{18}$ This technique holds great promise to reduce rates of PGD as more insight is gained into its pathogenesis.

The persistently high rates of PGD affecting our lung transplant recipients is an alarming fact clearly indicating that research efforts need to be directed toward studies in this field that would provide mechanistic insight into its pathogenesis. Our study confirms that PGD adversely affects early outcomes as evidenced by increased hospital mortality and inferior survival at 1 year. In addition, 10year survival in patients with PGD is approximately $50 \%$ lower than those of recipients without this complication. Our findings support and extend previous reports from our institution that have examined long-term consequences of PGD. In a retrospective analysis of 334 adult lung transplant recipients, Daud and colleagues ${ }^{19}$ found that all grades of PGD assessed immediately after transplantation were associated with an increased risk of developing BOS inde-
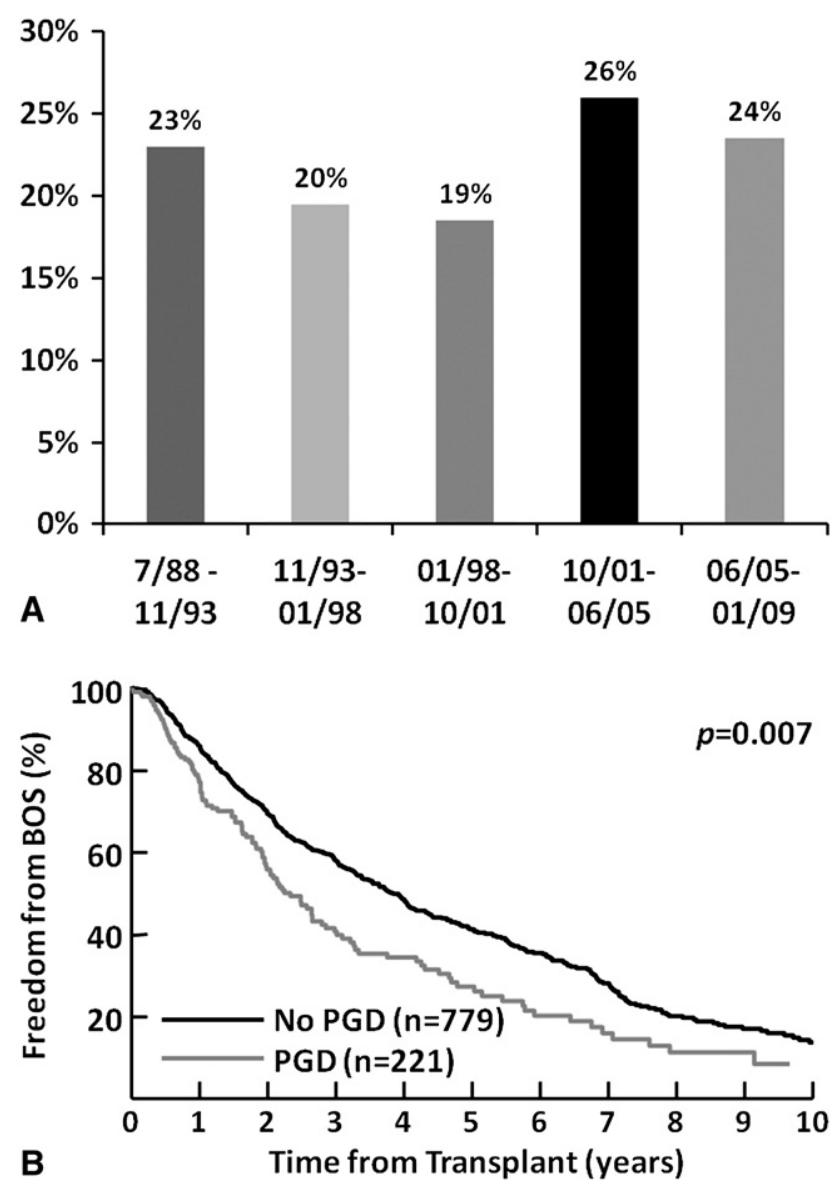

FIGURE 2. A, Incidence of PGD presented for individual quintiles. B, Survival after lung transplantation stratified by PGD. BOS, Bronchiolitis obliterans syndrome; $P G D$, primary graft dysfunction.

pendently of other factors, including acute rejection, lymphocytic bronchiolitis, and respiratory viral infections. Huang and colleagues ${ }^{20}$ followed up on this observation and reported that in the same cohort of patients all grades of PGD at 24, 48, and 72 hours after transplantation are significant risk factors for the development of BOS. ${ }^{20}$

Our case series clearly illustrates that BOS, widely considered to represent a manifestation of chronic allograft rejection, remains the Achilles' heel of lung transplantation. Strikingly, the rates of freedom from BOS at 1 and 3 years have remained virtually unchanged throughout the duration of our experience. Clinical studies have suggested that both alloimmune events, such as acute rejection and lymphocytic bronchiolitis, as well as non-alloimmune factors, such as PGD, gastroesophageal reflux, and respiratory viral infections, contribute to the development of this condition. ${ }^{19}$ Our findings that patients who had PGD had higher rates of BOS support an association between these 2 conditions. It is intriguing that a clinical study from Duke University demonstrated that lung recipients with Toll-like receptor 4 polymorphisms that are associated with hyporesponsiveness to endotoxin had fewer episodes of acute rejection and 

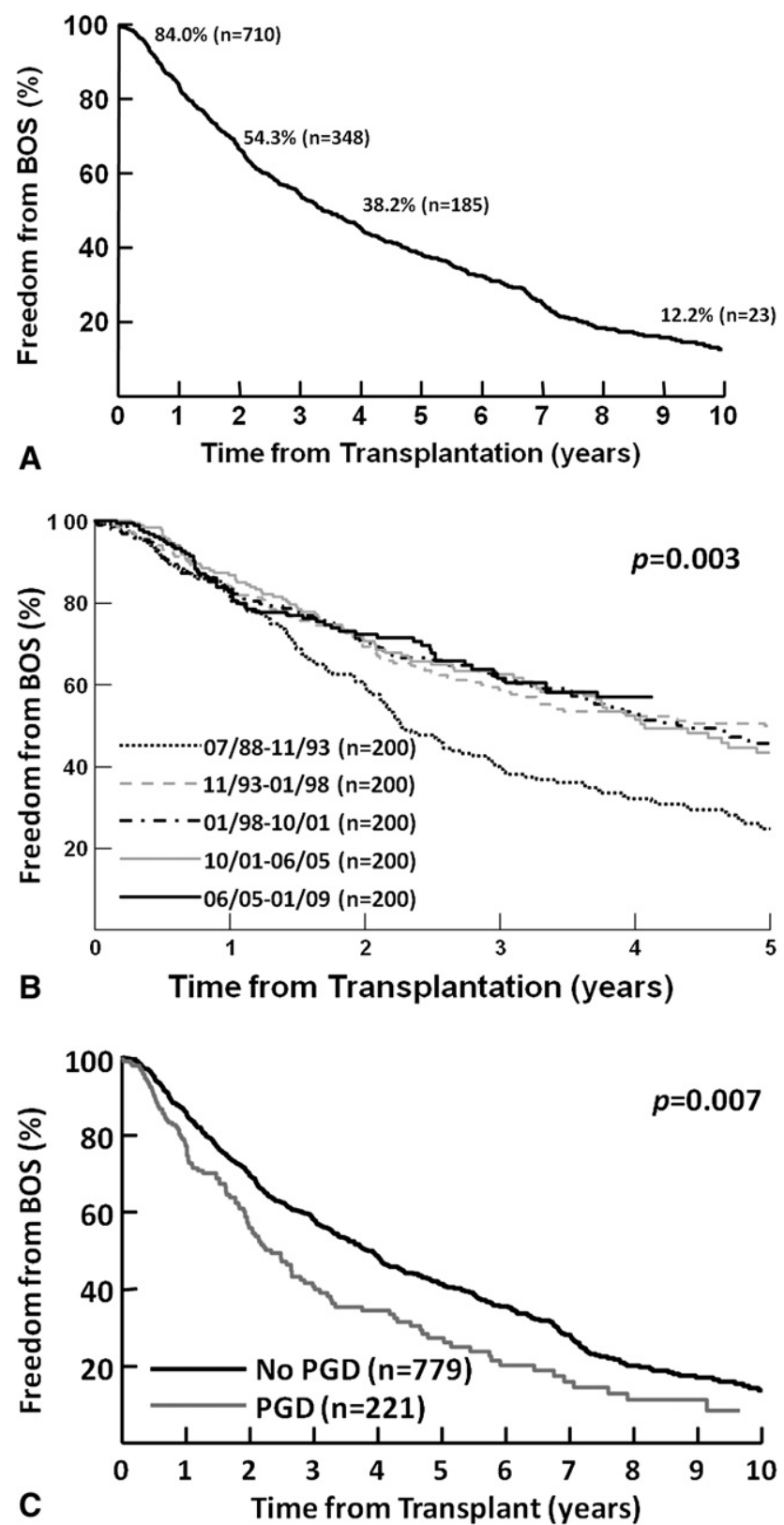

FIGURE 3. A, Freedom rates from BOS $(n=1000)$. B, Freedom rates from BOS stratified by era. C, Freedom rates from BOS stratified by PGD. BOS, Bronchiolitis obliterans syndrome; $P G D$, primary graft dysfunction.

a trend toward increased BOS-free survival. ${ }^{21}$ Endogenous ligands that are released during ischemia-reperfusion injury can signal through Toll-like receptor 4 and ischemia-reperfusion injury is attenuated in Toll-like receptor 4-deficient animals, raising the possibility that innate immune receptors provide a link between PGD and graft rejection. ${ }^{22,23}$

The increasing number of patients dying on the waiting list, in large part resulting from a relative shortage of donor organs, was one of the main driving forces to change the allocation system of lungs. An important criticism of the old allocation system that was based primarily on time accrual on the waiting list was that many patients were listed for lung transplantation during relatively early stages of their disease, which resulted in the death of more critically ill patients. To this end, the lung allocation score was implemented in 2005, which took into consideration the probability of survival on the waiting list and predicted survival after pulmonary transplantation. On the basis of data from 5 centers, including our own, Kozower and colleagues ${ }^{24}$ reported short-term outcomes of the impact of the lung allocation score. There has been a relative increase in transplants for pulmonary fibrosis and a relative decrease in transplants for COPD and cystic fibrosis since the introduction of the lung allocation score. The time on the waiting list decreased significantly from 681 to 446 days, and the number of patients on the waiting list has decreased substantially. ${ }^{25}$ Not surprisingly, the number of retransplantations has dramatically increased because critically ill patients who have previously received lung grafts can have high allocation scores. Although higher allocation scores at the time of transplantation are associated with worse outcomes, there exists some controversy about the impact of the lung allocation score on 1-year survival. ${ }^{24,26}$ At our center, the 1- and 3-year survivals have decreased during the fifth quintile, which temporally coincides with the implementation of the lung allocation score. Clearly, long-term data are necessary to better define the consequences of the lung allocation score.

\section{CONCLUSIONS}

Although we have observed improvements in long-term survival since the inception of our program, many challenges remain in lung transplantation. The prospect of reconditioning marginal lungs holds great promise to expand the donor pool. It also opens an exciting avenue into therapeutic interventions before implantation. Advances in treatment and prevention of PGD and graft rejection, 2 of the main obstacles to long-term success, will undoubtedly depend on basic science investigations. Dissection of cellular and molecular mechanisms that contribute to complications in human lung recipients will be facilitated by recently developed murine models and existing preclinical large animal models of lung transplantation. ${ }^{27-29}$

\section{References}

1. Christie JD, Edwards LB, Aurora P, Dobbels F, Kirk R, Rahmel AO, et al. The Registry of the International Society for Heart and Lung Transplantation: Twenty-sixth Official Adult Lung and Heart-Lung Transplantation Report-2009. J Heart Lung Transplant. 2009;28:1031-49.

2. Meyers BF, de la Morena M, Sweet SC, Trulock EP, Guthrie TJ, Mendeloff EN, et al. Primary graft dysfunction and other selected complications of lung transplantation: a single-center experience of 983 patients. J Thorac Cardiovasc Surg. 2005;129:1421-9.

3. Hachem RR, Yusen RD, Chakinala MM, Meyers BF, Lynch JP, Aloush AA, et al. A randomized controlled trial of tacrolimus versus cyclosporine after lung transplantation. J Heart Lung Transplant. 2007;26:1012-8. 
4. Jain R, Hachem RR, Morrell MR, Trulock EP, Chakinala MM, Yusen RD, et al. Azithromycin is associated with increased survival in lung transplant recipients with bronchiolitis obliterans syndrome. J Heart Lung Transplant. 2010;29: 531-7.

5. Morrell MR, Despotis GJ, Lublin DM, Patterson GA, Trulock EP, Hachem RR. The efficacy of photopheresis for bronchiolitis obliterans syndrome after lung transplantation. J Heart Lung Transplant. 2010;29:424-31.

6. Cassivi SD, Meyers BF, Battafarano RJ, Guthrie TJ, Trulock EP, Lynch JP, et al. Thirteen-year experience in lung transplantation for emphysema. Ann Thorac Surg. 2002;74:1663-9.

7. Thabut G, Christie JD, Ravaud P, Castier Y, Brugiere O, Fournier M, et al. Survival after bilateral versus single lung transplantation for patients with chronic obstructive pulmonary disease: a retrospective analysis of registry data. Lancet. 2008;371:744-51

8. Hadjiliadis D, Chaparro C, Gutierrez C, Steele MP, Singer LG, Davis RD, et al. Impact of lung transplant operation on bronchiolitis obliterans syndrome in patients with chronic obstructive pulmonary disease. Am J Transplant. 2006;6:183-9.

9. Nwakanma LU, Simpkins CE, Williams JA, Chang DC, Borja MC, Conte JV, et al. Impact of bilateral versus single lung transplantation on survival in recipients 60 years of age and older: analysis of United Network for Organ Sharing database. J Thorac Cardiovasc Surg. 2007;133:541-7.

10. Pochettino A, Kotloff RM, Rosengard BR, Arcasoy SM, Blumenthal NP, Kaiser LR, et al. Bilateral versus single lung transplantation for chronic obstructive pulmonary disease: intermediate-term results. Ann Thorac Surg. 2000;70: 1813-8.

11. Granton J. Update of early respiratory failure in the lung transplant recipient. Curr Opin Crit Care. 2006;12:19-24.

12. Wittwer T, Albes JM, Fehrenbach A, Pech T, Franke UF, Richter J, et al. Experimental lung preservation with Perfadex: effect of the NO-donor nitroglycerin on postischemic outcome. J Thorac Cardiovasc Surg. 2003;125:1208-16.

13. Nath DS, Walter AR, Johnson AC, Radosevich DM, Prekker ME, Herrington CS, et al. Does Perfadex affect outcomes in clinical lung transplantation? J Heart Lung Transplant. 2005;24:2243-8.

14. Fischer S, Matte-Martyn A, De Perrot M, Waddell TK, Sekine Y, Hutcheon M, et al. Low-potassium dextran preservation solution improves lung function after human lung transplantation. J Thorac Cardiovasc Surg. 2001;121:594-6.

15. Whitson BA, Nath DS, Johnson AC, Walker AR, Prekker ME, Radosevich DM, et al. Risk factors for primary graft dysfunction after lung transplantation. J Thorac Cardiovasc Surg. 2006;131:73-80.

16. Puri V, Scavuzzo M, Guthrie T, Hachem R, Krupnick AS, Kreisel D, et al. Lung transplantation and donation after cardiac death: a single center experience. Ann Thorac Surg. 2009;88:1609-14.

17. Erasmus ME, Verschuuren EA, Nijkamp DM, Vermeyden JW, van der Bij W. Lung transplantation from nonheparinized category III non-heart-beating donors. A single-centre report. Transplantation. 2010;89:452-7.

18. Cypel M, Liu M, Rubacha M, Yeung JC, Hirayama S, Anraku M, et al. Functional repair of human donor lungs by IL-10 gene therapy. Sci Transl Med. 2009;1:4-9.

19. Daud SA, Yusen RD, Meyers BF, Chakinala MM, Walter MJ, Aloush AA, et al. Impact of immediate primary lung allograft dysfunction on bronchiolitis obliterans syndrome. Am J Respir Crit Care Med. 2007;175:507-13.

20. Huang HJ, Yusen RD, Meyers BF, Walter MJ, Mohanakumar T, Patterson GA, et al. Late primary graft dysfunction after lung transplantation and bronchiolitis obliterans syndrome. Am J Transplant. 2008;8:2454-62.

21. Palmer SM, Burch LH, Trindade AJ, Davis RD, Herczyk WF, Reinsmoen NL, et al. Innate immunity influences long-term outcomes after human lung transplant. Am J Respir Crit Care Med. 2005;171:780-5.

22. Tesar BM, Jiang D, Liang J, Palmer SM, Noble PW, Goldstein DR. The role of hyaluronan degradation products as innate alloimmune agonists. Am J Transplant. 2006;6:2622-35.

23. Shimamoto A, Pohlman TH, Shomura S, Tarukawa T, Takao M, Shimpo H. Tolllike receptor 4 mediates lung ischemia-reperfusion injury. Ann Thorac Surg. 2006;82:2017-23.

24. Kozower BD, Meyers BF, Smith MA, De Oliveira NC, Cassivi SD, Guthrie TJ, et al. The impact of the lung allocation score on short-term transplantation outcomes: a multicenter study. J Thorac Cardiovasc Surg. 2008;135:166-71.

25. McCurry KR, Shearon TH, Edwards LB, Chan KM, Sweet SC, Valapour M, et al. Lung transplantation in the United States, 1998-2007. Am J Transplant. 2009;9 (4 Pt 2):942-58.

26. McCue JD, Mooney J, Quail J, Arrington A, Herrington C, Dahlberg PS. Ninetyday mortality and major complications are not affected by use of lung allocation score. J Heart Lung Transplant. 2008;27:192-6.
27. Okazaki M, Krupnick AS, Kornfeld CG, Lai JM, Ritter JH, Richardson SB, et al A mouse model of orthotopic vascularized aerated lung transplantation. Am J Transplant. 2007;7:1672-9.

28. Sato M, Hirayama S, Hwang DM, Lara-Guerra H, Wagnetz D, Waddell TK, et al The role of intrapulmonary de novo lymphoid tissue in obliterative bronchiolitis after lung transplantation. J Immunol. 2009;182:7307-16.

29. Meltzer AJ, Weiss MJ, Veillette GR, Sahara H, Ng CY, Cochrane ME, et al Repetitive gastric aspiration leads to augmented indirect allorecognition after lung transplantation in miniature swine. Transplantation. 2008;86:1824-9.

\section{Discussion}

Dr Shaf Keshavjee (Toronto, Ontario, Canada). Dan, congratulations on an excellent presentation. I would like to congratulate your whole group. Certainly Joel Cooper and Alec Patterson have led the world in making lung transplantation a clinical reality. What you have demonstrated is that lung transplantation can be made a more routine operation, and you've provided a benchmark in your results.

You talked about the incidence of PGD and its effect on chronic graft dysfunction or BOS. Did you actually look at the grades of PGD? Is it just the grade 3 PGDs that give you the poorer longterm outcome or is it any PGD?

Dr Kreisel. There were 2 articles published from our institution over the last few years, one by Daud and colleagues a few years back in which he showed that all grades of PGD immediately postoperatively were independent risk factors for the development of BOS, and Huang and colleagues recently followed up in an article published in the American Journal of Transplantation in which he showed that all grades of PGD at 24, 48, and 72 hours postoperatively were independent risk factors for the development of BOS. So at least in our institution, all grades seemed to correlate with the development of late graft dysfunction.

Dr Keshavjee. I think that is an important point, because one of the concepts that has emerged in recent years is our understanding that late graft dysfunction is not just allograft rejection, but a multifactorial process that relates to the early events as well.

My second question, you mentioned your experience with DCD lungs and the fact that the incidence of severe grade 3 PGD was $35 \%$, or twice that in your brain-dead donor lungs. Currently, many people in the field have gone so far as to say that DCD lungs are equivalent donor lungs, or some even say that they are superior to brain-dead donor lungs. What have you learned from your experience that you can share with us in terms of what you define as a high-risk DCD lung?

Dr Kreisel. I don't have a great answer for this. Our series that we published last year included only 11 or 14 DCD donors with a high incidence of PGD, and I don't have the data on whether the ischemic times were very long or whether there were any other factors, and I know that other studies do not mirror this experience. I think that as we accumulate more numbers, we may get a better idea. But along the same lines, there are many events in the donor, except for the DCD aspect, that we just don't understand what predicts the development of PGD, and there is a lot of work to be done there. So I think it was just a small series, and I don't know whether it's reflective of what we will see in the future.

Dr Keshavjee. The introduction of the lung allocation score certainly has affected your program and changed the type of patients who undergo transplantation. The indication for transplant diagnosis has shifted from predominantly emphysema to more idiopathic pulmonary fibrosis and higher scoring patients, but I was surprised 
to see that it hasn't affected your waiting time, with your waiting time still being more than 1.5 years. I thought that the system was going to help to sort that out in the United States. Do you have any insights as to why it has not affected your program?

Dr Kreisel. It has affected the program. The mean waiting time decreased from in excess of 600 days to 550 days, but why it is significantly longer than, for example, what you experience, I don't have an answer for that.

Dr Keshavjee. Well, just for the information of the audience, in the United States the waiting time varies from less than 1 month to more than 1.5 years across the country, so it does reflect that we haven't totally fixed the problem with the lung allocation score.

Dr Raphael Bueno (Boston, Mass). You demonstrated that there are different overall survivals based on the era, there was a difference in the survival between a double and a single lung, and there was a change when you moved more to double lungs, if I recall. Did you take that into consideration when you showed a difference in survival? You showed a 10-year follow up as opposed to a 15-year follow-up on that slide.

Dr Kreisel. I'm afraid I don't understand your question.

Dr Bueno. Was there any time bias that could have explained some of the differences you saw in this particular series in the survival long range between a double and a single lung transplant?

Dr Kreisel. No. I think the survival difference between bilateral and single lung transplantation for emphysema and fibrosis is seen by virtually all centers, and the centers that do not do bilateral transplants do it according to availability of donor organs. So we have seen a consistently better survival with bilateral lung transplants than with single lung transplants, and I know of studies from Duke and Toronto in which bilateral lung transplants were also correlated with lower incidence of BOS, which may provide an explanation in addition to just having larger lung mass and lung capacity.

Dr Dirk Van Raemdonck (Leuven, Belgium). I'm interested in knowing your strategies and techniques for extracorporeal support if needed during transplantation. Has that changed over the years?

Dr Kreisel. You mean implementation of extracorporeal membrane oxygenation if....

Dr Shrager. The use of bypass.

Dr Kreisel. We do not use elective bypass. The implementation of cardiopulmonary bypass is either done on the basis of parameters during the implantation or on preoperative parameters, but there is no planned use of cardiopulmonary bypass at our center.

Dr Van Raemdonck. And are you using central cannulation or peripheral?

Dr Kreisel. Central cannulation.

Dr Stephen Cassivi (Rochester, Minn). Dan, this is excellent. You are part of a great team, obviously. I have 2 questions.

One, with regard to the PGD, you were stating in your presentation that it has an effect on long-term and you showed us a curve. What I saw was that the curve drops early, as we would expect, but the curve later on is parallel. I don't know whether that long-term survival is just because they have such poor short-term survival. Did you do anything to statistically show that after that, the conditional survival is worse?

Dr Kreisel. I don't think we did that analysis, but what I can tell you is that at least in the experimental setting we have evidence that those early events alter the adaptive immune response, and the adaptive immune response is changed at late time points in animal models based on early PGD due to some interplay between innate and adaptive immune responses. So I don't think it's just a matter of the early mortality as to why we see late failure in patients who had PGD. I think there is obviously an early drop-off.

Dr Cassivi. I think you're right, and intuitively we would think that's the same, but it might be interesting to look at the conditional survival.

My second question is with regard to the lung allocation score and how that has changed, and we see the drop-off at your institution, just like at ours and others, in those with COPD and how there is a preference for the diseases other than COPD. In the recent history, have you noticed an increase in your wait-list mortality for the patients with COPD?

Dr Kreisel. I don't have the data. I do not think we have had an increased mortality for patients with COPD, but I don't have that data.

Dr Daniel Mason (Cleveland, Ohio). I was a little surprised that among 1000 transplants, only 20 were retransplants, and I think only a handful of those were for BOS, and obviously there is a lot of BOS out there. I was just curious about the Washington University philosophy on retransplant and who is a candidate for retransplant.

Dr Kreisel. Well, we list the patients with BOS for retransplants. Why the number is so low, I don't know. Recently we started doing some photopheresis for BOS with some mild improvement in outcomes, but I guess....

Dr Sugarbaker. The question is who would you consider for a retransplant given the higher operative mortality and the lower overall survival? Are all patients considered for retransplant should they have graft failure early? How far out do you let them go? Are there any issues around that that you could elucidate?

Dr Kreisel. I don't know exactly why we haven't done more retransplants. We certainly have a lot of patients with BOS listed for retransplants. I don't have an answer as to why the number has been relatively low.

Dr Marcelo Cypel (Toronto, Ontario, Canada). Dan, that was a nice presentation.

Do you have any numbers on PGD3 requiring extracorporeal membrane oxygenation, and what were the outcomes of those patients who underwent....

Dr Kreisel. I don't have those numbers of how many patients required it.

Dr Antoon Lerut (Leuven, Belgium). Over the recent years, there has been a focus of interest on the relation between reflux and BOS. Have you seen in your last cohort of patients an impact of your antireflux therapy, whether it's medical or surgical, on the incidence of BOS and did it made a difference?

Dr Kreisel. We haven't analyzed this specifically, as far as I know, but we have been far more liberal offering fundoplications to patients on the waiting list and early fundoplications in patients who underwent lung transplantation.

Dr Lerut. Can you give us an idea about the fraction of patients who are receiving an antireflux operation nowadays?

Dr Kreisel. I don't know the exact number, but we have been fairly liberal with that. 